\title{
What New And Adjunct Faculty Need To Know About Exams, Grades, And Cheating
}

Rick Berschback, Walsh College, USA

\begin{abstract}
College professors often regard their time in the classroom fulfilling and rewarding; the chance to affect the academic and professional development of their students is most likely a key reason why they chose to be professional educators. Unfortunately, with college courses come college credits, which necessitate a course grade for each student, which necessitates student assessment vehicles, such as exams. More unfortunately, those exams lead to the potential for student cheating.

Some professors, particularly new and/or adjunct professors, underestimate the importance of exams and the resulting determination of student grades. Unless proper attention is paid to exam construction and the possibility of academic misconduct by students taking exams, course grades can be a misrepresentation of student abilities and competencies.

This paper is the second of a two-part series. Both papers are user-friendly manuals designed to minimize the growing pains associated with college-level teaching, especially those experienced by adjunct instructors. With this information, instructors can better anticipate the challenges involved in assigning appropriate grades and meet the course objectives. Specific topics of this segment include exam development and administration, options for timing and scheduling exams, student cheating and methods to prevent cheating, and the overall strategies for course grading.

The first part of the two-part series, "Everything That New And Adjunct Business Faculty Members Should Ask About Teaching, But Don't Know Enough To Ask," was published in the May 2010 Journal of College Teaching and Learning. Topics include syllabus development, classroom teaching methods, efficient use of classroom time, and general classroom management.
\end{abstract}

Keywords: exam formats; exam administration; cheating; methods to prevent cheating

\section{INTRODUCTION}

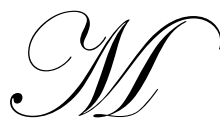

any college professors will admit that the chance to participate in the academic and professional development of students is one of the reasons they are educators. Whether through delivering classroom lectures, leading student group discussions, or mentoring students needing guidance, professors have a unique opportunity to have a positive impact on the lives of many individuals.

Many college professors will also admit that their careers would be even more fulfilling if there was no need to determine student grades. The need for each student to be evaluated is regarded as a necessary evil, requiring methods of student assessments that take time and focus away from the process of learning.

However, grades are absolutely necessary. Although one can argue they are not pure indicators of a student's achievement in a course or of a student's potential for subsequent success in college and beyond, they are the primary measure of academic achievement used to determine completion of undergraduate and graduate degrees. Perhaps more significant is that grades will be reviewed and considered by any educational institution from which the student seeks a higher-level degree, as well as by any potential employer when the student applies for a careerstarting position. 
Therefore, professors should consider the determination of student grades a critical component of their course responsibilities. Strict grading scales and high expectations can encourage students to put forth greater effort in their classroom performance, thereby acquiring a better understanding of the subject matter (Elikai, 2010).

Exams represent a major component of course grades in many business courses. Careful consideration should be given to the construction, level of rigor, length, and timing of exams. If exams comprise a significant portion of a student's course grade, for students to be very grade-conscious should be no surprise.

With that grade consciousness comes the inevitable possibility of cheating on exams. Professors who ignore this possibility are assured of only one result: student cheating will never be detected. Cheating is certainly not a new phenomenon. Yet, the difference between today's environment and that of yesteryear is that cheating behavior is now considered commonplace and not an exception to the norm (Crittenden, 2009). When students know that other students are benefitting from cheating, some students are more compelled to cheat. The result is that the grading system used to promote success is also used as a motivation for academic misconduct (Owunwanne, 2010).

Adjunct professors and full-time professors new to teaching should avoid the temptation to assign only high grades in order to increase their popularity as instructors. This author has taught for 30 years at a school placing significant reliance on adjunct faculty, with most of the 30 years as accounting department chair. For the department to meet its goals, the adjunct professors must focus on student assessment vehicles (predominantly exams) that result in representative grades. These grades cannot be affected by the rare but significant impact of the student who cheats on exams or has received exam information in advance from other students or other sources.

\section{SECTION ONE: EXAMS}

The instructor has the responsibility to develop and implement the proper vehicles that will serve as the basis for determining each student's grade for the course. The common trap that some instructors fall into is the use of a standardized exam; this type of exam often requires the least amount of work for instructors. For some courses, standardized exams can result in an appropriate reflection of a student's performance. However, obtaining appropriate exams from standard sources is sometimes difficult, especially for courses beyond the fundamental levels. The burden is then on the instructor's shoulders to obtain or develop an appropriate test method.

Another problem is the re-use of exams from term to term. There are benefits to using a well-developed exam more than once; expecting a new set of exams to be developed each term is unrealistic, especially for part-time instructors. However, grade-conscious students often ask fellow students for information regarding past exams. Students from prior semesters may have accumulated exam banks and have made them available to current students.

The negative impact is significant. First, undeserving students receive high grades only because they secured the questions (and answers) in advance. The hard-working students, who were not privy to exam information, are unjustly punished; they score lower on the "curve" than they should.

Second, the common knowledge that exam information is available "through the grapevine" will promote efforts to search for that information. Students will consider this "information-sharing" more critical than what they should be doing to perform well on exams: learning the material.

Similar problems exist when an instructor is teaching multiple sections of the same course. The use of the same exam in all sections can result in information being passed from student to student.

The above practices of information-sharing represent behavior far from ethical. However, instructors should be aware of the following:

1. Some students do not consider information-sharing unethical, as it is all done outside of class. Students who took the exams consider all information "common knowledge."

2. Even if information-sharing is considered unethical, students will succumb to peer pressure and grade pressure. 
3. The possibility exists that no sharing of information exists between students of different sections or different terms. However, once the instructor ignores the possibility of this information-sharing, the door is open for it to occur; good, ethical students will be penalized while those who do not learn the material will be rewarded.

\section{SECTION TWO: EXAM FORMATS}

The objective and format for exams will differ from course to course. The instructor should be aware of the different types of exam questions, the advantages and disadvantages of each type, and the impact of these choices on the effectiveness of the exam. Designing an exam that is representative of the course objectives should be the goal of the instructor. Methods of testing, difficulty levels of questions, length of the exams, and frequency of testing are factors to be considered. The common types of questions are true/false, multiple-choice, and essays/problems.

\section{True/False Questions}

True/False questions can address many topics in a relatively short period of time. The disadvantage is the nature of the question: if any part of the statement is false, the correct answer is "False." Some discriminating readers can usually find fault with or exception to something in any statement. These students are penalized severely for interpreting the statement in a slightly different manner than intended. For this reason, most professional examinations avoid the use of True/False questions, as establishing validity and reliability for this type of question is difficult.

Still, True/False questions are very efficient in testing a large number of specific topics that focus on basic knowledge (with little room for varying interpretations). Their validity can be enhanced by forcing students to explain their answers with short narratives (Kwan, 2010).

\section{Multiple-Choice Questions}

This type of exam question is very popular at the college/university level and in professional exams; multiplechoice questions can present an arithmetic problem or a theoretical question while still being easy to grade. Questions testing application of concepts may be better assessments of student abilities than those testing rote memorization. Application-type questions ask students to grapple with scenarios and recognize concepts in context, making the multiple-choice format more difficult than essays for many students (Holtzman, 2008).

One advantage of multiple-choice (compared to True/False) is that the best of four or five answers presented is to be selected, even if the discriminating reader can think of an even better answer not displayed. In True/False questions, the discriminating reader selects the wrong answer and is penalized. In multiple-choice, the discriminating reader who goes beyond the scope of the question will, at first, consider all answers unacceptable. This reader would then re-read the problem using a different interpretation and is granted another chance at arriving at the correct answer. Of course, this gift of a "second chance" could be considered a disadvantage of using multiple- choice questions. A student who derives a wrong answer that is not one of the "distractors" tries again.

Multiple-choice questions with answer choices of "all of the above" and/or "none of the above" are sometimes risky. The selection "all of the above" often is confusing, unless "all" answers are correct on an equal, proportional basis. Also confusing is whether "all of the above" indicates that each answer is individually correct or that all answers are needed to compile the correct answer.

"None of the above," similar to True/False, penalizes the student who interprets the question incorrectly or analyzes beyond the intent of the question. That student finds at least a slight fault in each given answer and chooses "none of the above." This is the same answer chosen by an unprepared student who has no idea how to arrive at any one of the given answers and, accordingly, chooses "none of the above."

Even though multiple-choice questions allow students to sometimes choose the correct answer by guessing, most of these questions are designed so that the probability of the student choosing the correct answer is related to the student's knowledge and ability. 
For example, assume a question has five answers (A through E) from which to select:

- $\quad$ Answers A, B, and C are based on a fundamental error in applying the knowledge tested in the question.

- $\quad$ Answer $\mathrm{D}$ is based on a minor error in the specific analytical process used in deriving the answer.

- $\quad$ Answer $\mathrm{E}$ is the correct answer.

The result is that students who lack the basic knowledge tested by the question arrive at answer A, B, or C (or none of the selections A through E). They consequently select the wrong answer (or have at most a $20 \%$ chance of guessing). The good students will automatically eliminate answers A through $\mathrm{C}$ and be torn between answers $\mathrm{D}$ and $\mathrm{E}$; at this point, they have a 50\% chance of earning full credit for the question. Of course, the excellent student will select answer $\mathrm{E}$ and receive full credit.

The weak students are guessing at the $20 \%$ level, while the stronger students are able to guess at the $50 \%$ level. The excellent students score near $100 \%$. Of course, the variety of questions on an exam and the different difficulty levels of the questions prevent the formation of three distinct groups (20,50, and 100\%). Still, there is a sense of "partial credit" if the multiple-choice answers are designed using the approach described above.

\section{Essays/Problems}

Essays and problems are non-objective in nature; they are combined in the following discussion because they share several characteristics.

Essays are arguably the most thorough and fairest vehicles to evaluate student performance, and no one can question the importance of allowing writing skills to be an element of the exam grade. Many students are aware that, when compared to answering objective multiple-choice, essay writing involves a higher order of intellectual skills (Scouller, 1998).

Due to the time required to grade essays, using them extensively in assessing student performance may not be possible. However, many academic departments should consider the development of "writing skills" a department responsibility and, accordingly, should include essays in the student assessment vehicles of appropriate courses.

One drawback of essay exams is the subjectivity required in grading essays and awarding points. Also, the instructor is sometimes over-influenced by neatness and handwriting. Another disadvantage of using essays is that a relatively long time period is used to test a relatively small amount of material. Still, an essay answer best represents the student's mastery of the material; the student is given no chance of guessing and no prompting words or sentences relating to the topic - just a blank sheet of paper.

When grading essay answers, consistency is critical. The instructor should review a sample of essay answers prior to determining the "grading key" for the exam. This will give the instructor an idea of what to allow or disallow when awarding points for each essay. To increase consistency, Question \#1 should be graded for all student papers before moving to Question \#2.

If possible, a "key" in the form of an outline of a "model" answer should be developed when creating the exam. Once the major ideas are outlined, assigning points to each question and determining how partial credit will be awarded becomes easier.

Problems requiring computation and analysis have qualities similar to essay questions. Students must demonstrate thorough and complete knowledge because they are starting with a virtual blank sheet. The problem format appropriately rewards those students who have developed organizational skills and written presentation techniques.

For the instructor, the same concerns that exist for essay questions must be addressed: the subjective nature of grading, the allowing of partial credit, and the needed consistency in awarding points. 


\section{Rigor Levels And Question Variety}

Regardless of the "mix" of different types of questions, the exam should offer questions with a variety of difficulty levels, especially if the exam is predominantly objective in nature.

For example, an exam consisting entirely of very difficult questions will reward the excellent student with a high grade, but the good student and the unprepared student will both perform poorly because both students were below the adequate level of knowledge required by each question. In this case, the good student and the poor student receive nearly the same score; the exam did not meet its objective.

Conversely, an exam consisting of entirely easy questions will not differentiate between the good student and the excellent student. The exam must therefore be designed to properly differentiate between the different levels of student competencies.

In addition to selecting exam questions that represent different levels of difficulty, the exam should be designed to test various "types" of learning related to the material. Questions that test definitions of terms should not form the basis of the entire exam. Application skills and conceptual understanding should also be tested.

Exams should not include two or more questions that cover the same material with no significant difference in analytical skills needed to solve for the answers. If there are two questions on the same topic, one question should require an elementary understanding and the other should require a detailed understanding.

Exams should be representative of the material included in the course objectives, as well as material stressed in lectures and homework. Students must realize that memorization of lecture notes and homework is insufficient to adequately perform on the exams. Some material not covered during class (but included in texts or required readings) should be tested on examinations.

\section{SECTION 3: EXAM ADMINISTRATION}

Instructors must not risk the validity of exams by relying on last-minute preparations. Proofreading and reviewing each question is necessary. Exams are extremely important to the students; they should be considered even more important by instructors.

All desktops should be cleared before exams are distributed. Calculators with data-storage features should not be allowed.

Exams should be distributed face down so that some students cannot begin well before others. This will allow application of the start-up procedures noted below and also assure that all students receive equal time for the exam.

Prior to starting, instructors should spend a few moments reviewing individual pages, announcing the components of the exam. The students should "flip" pages along with the instructor. These few moments can also uncover any exams with missing pages, unreadable pages, or collating errors.

Students should be reminded of the time limit and that it will be enforced. All students must understand that no extra time will be allowed beyond the prescribed time limit, including extra time for transferring objective answers from the exam to the separate objective answer sheet.

\section{SECTION 4: TIMED EXAMS}

Although most students will complain that the time limit adversely affects their score, the fact that they were forced to work under pressure is certainly representative of the real-world situations they will encounter following graduation. A time limit on the exam appropriately rewards those students who think and analyze using the most efficient methods available. 
Estimating the required time for an exam is not easy. Some instructors fail to adhere to the announced time limit for the exam. To illustrate, assume a 90-minute exam is nearing the ending time and several students have not finished; the instructor then announces a twenty-minute extension for the exam, thinking that the decision will be fair to all students.

Consideration should be given to the effects of such a decision. It certainly will allow more students to answer more questions on the exam, thus increasing the average score on the exam. However, it could penalize the students who correctly budgeted their time and managed to complete the exam within the prescribed time limit. They would have difficulty pinpointing the exact question(s) to return to, and they would need to refamiliarize themselves with questions and their selected answers before they are able to use the extra time productively. The students who performed at a slower pace have no doubt what to do with the bonus time granted: use it on the exam sections they have yet to attempt.

If in doubt, the instructor should conservatively allow an adequate cushion. As the instructor becomes more familiar with the time students need to complete exams, the time allowed can be adjusted in future courses.

\section{SECTION 5: SCHEDULING OF EXAMS}

Most instructors determine the exam dates when planning the syllabus for the semester. Those dates should change only due to unusual circumstances, such as class cancellations or illness. Most students, especially adult students, need to plan their study strategies during the semester to coincide with the exam dates. Also, the appearance that the exam dates are flexible will result in students asking for postponements so that they can extend study time. Delaying the exam will therefore benefit those students who procrastinated in the weeks prior to the exam and penalize the students who properly planned and prepared.

If the class is behind schedule and the material planned for the upcoming exam has not been covered, the instructor must choose between giving the exam on the predetermined date (and including less material on the exam) or postponing the exam.

Postponing the exam will almost automatically result in the elimination of material to be covered during the course; there is now at least one less class meeting to complete the remaining material.

\section{SECTION 6: MAKE-UP EXAMS}

Developing a policy for make-up exams is always difficult. The instructor must select the policy appropriate for the course after careful consideration of the advantages and disadvantages of the various options. The policy must be included in the syllabus and followed throughout the semester.

Examples of make-up exam policies include the following:

1. $\quad$ No make-ups.

2. Make-ups allowed only with advance permission.

3. Make-ups allowed in cases of family sicknesses or deaths.

4. If you miss an exam, your score for that exam will be the average of your other exams (less a nominal number of points). This policy is most effective if all exams are cumulative, assuring that the student will be tested on the material covered by the missed exam.

5. Make-ups are allowed, but your score on the make-up cannot exceed your average score on all other exams.

6. Make-ups are allowed, and the make-up exam will likely be more difficult than the regularly scheduled exam.

Students who object to any "penalty" resulting from the make-up policy are probably ignoring two factors:

1. They are missing a critical class meeting, which should be adequate reason for an effect on their course grade. 
2. Make-up exams inherently jeopardize the validity of the exam process, since they create the potential for information-sharing among students.

If make-ups are allowed, the instructor must decide if a student's excuse for missing the exam is appropriate. To "draw the line" between acceptable and non-acceptable reasons is challenging. There is also the chance that students who did not prepare for the exam will take advantage of a liberal make-up policy. Many instructors avoid this by selecting a rigid policy that does not require them to pass judgment on the validity of the excuse.

The pros and cons of giving the make-up exam before the scheduled time versus after the scheduled time should be considered. Scheduling the make-up before the scheduled exam assures the instructor that the one student receiving special consideration is unaware of the format and specifics of the exam. However, allowing one student to take the exam before all others potentially releases the exam content to all students.

Scheduling the make-up after the exam date has the opposite effect: if information is shared, only one student will benefit. Unfortunately, the chance of that one student benefiting is significant! Also, that student has been granted extra preparation time for the exam.

Of course, a make-up exam can be given that is different than the exam given to the other students, eliminating the threat of information-sharing. However, the probability that the make-up exam is slightly easier or more difficult than the regular exam must now be considered.

One policy that lessens the impact of make-ups and promotes student learning is to make all exams cumulative. This policy has certain advantages:

- $\quad$ Students who miss an exam must study and learn the related material for all subsequent exams.

- If understanding of certain topics will be tested on more than one exam, the students will be more inclined to understand those topics.

- If the material for the course is cumulative in nature, exams are a reflection of all material covered through the date of the latest exam.

- Studying for the cumulative final exam is not an impossible task; only the most recent course material has not been tested repeatedly.

A policy to be avoided is the policy that allows any student to "skip" the final exam if that student is performing at a certain grade level. Even though certain students have mastered the material for the majority of the course, they should not be excused from any of the course assessments.

\section{SECTION 7: RETURNING EXAMS}

Exams should be returned to students as soon as possible. The students can benefit from the knowledge that they are performing satisfactorily or that they need to adjust their study methods for future exams. However, there is usually no fundamental or academic reason why exams must be returned the following class meeting; the instructor should not compromise the proper grading of each exam simply to return the exams by the next session.

Most instructors review all or part of the exams in class so that students realize their mistakes. However, a student's realization of errors made on the exam does not indicate that the student has now mastered the body of knowledge tested on that exam. A poor score must be followed by the student's adjustment of study methods, commitment, or exam-taking techniques in order for performance to improve.

Before returning exams, the instructor may benefit from a review of the results of individual questions to determine if certain questions were very easy or very difficult. (Machine-graded objective questions often allow for automatic item analysis.) One reason for this is to assist in planning the level of rigor for future exams; if the exam needs to be easier or more difficult in subsequent semesters, which questions to eliminate and which to keep can be based on this analysis. 
This identification can also help increase efficiency when exams are returned to the students and reviewed. Easy questions should not require much attention. Difficult questions may require detailed explanation of the correct answer. Questions answered incorrectly by a large percentage of students (especially the excellent students) may indicate an invalid question or a question that will be "challenged" by students upon return of the exams. Although a high percentage of erroneous answers is certainly no reason to "throw out" a question, the instructor should be prepared to support the correct answer with something more than "that's the official answer."

During the review of the exams in class, students will sometimes debate or argue the validity of an exam question or official answer. The instructor should certainly consider any appeal or protest and review the question and answer, although that review need not occur during the class session. To listen to the student and understand the basic reasons for the appeal is sufficient at this time; the instructor should research the validity of the question and answer, returning with a decision as soon as possible.

Allowing a "second answer" to a question or "throwing out" a question should rarely occur. Obviously, allowing a student appeal will encourage other students to protest additional questions. For students to complain that a question is "tricky" is no indication the question is invalid.

When returning the exams in class, the confidentiality of each student's score must be retained by returning exams individually. This confidentiality rule should be applied to any exams, quizzes, and case projects which affect a student's final grade for the course.

If grades are "posted", the information must remain confidential. Any list should not be in alphabetized roster order, since it may reveal the grades of certain students. (Everyone will figure out that Abby Aaron's grade is on top of the list.) The roster should be separated into at least three parts and then scrambled before posting. College policy must be followed if posting grades on a website or via email.

\section{SECTION 8: METHODS OF CHEATING}

The instructor should protect the validity of the exams and corresponding grades by understanding that cheating on exams can occur. A good, hard-working student can easily be discouraged when witnessing another student cheating.

Instructors should also be aware of cheating methods used by students; this awareness will help prevent cheating situations and will be valuable if cheating incidents unfortunately occur.

Most students look at the instructor (or proctor) immediately prior to their attempt to copy an answer from a neighbor's paper. Any student who constantly looks up is one who should be watched carefully. Also, any student who repeatedly shields his or her eyes from view with a free hand should receive attention. The wearing of baseball caps or other hats with brims should not be allowed.

Cheating is much more efficient and effective when done near the end of the exam. More answers are available from other students; they have completed most of the exam. Also, a student who has not completed or performed well on the exam realizes that cheating may be needed to improve the exam grade.

Therefore, there should be a heightened awareness of cheating possibilities near the end of the exam time. The final few minutes can sometimes be hectic, with students submitting exams and diverting the instructor's attention; this diversion gives students the chance to copy from other students.

Constant eye contact with all students is important. The instructor or proctor should not leave the room or be buried in a good book.

If a student has a question during the exam, the student should approach the instructor (instead of the instructor approaching the student) so that the instructor's constant eye contact with other students can be maintained. 
If cheating is suspected, the academic department should have specific directions on the prescribed procedures to be followed. In most cases, this would include simply observing and noting the suspicious action. Usually, the student should not be delayed, singled out, or prevented from completing the exam (unless the evidence of cheating can only be obtained by taking action at that moment, such as taking "cheat notes" from the student).

Following the incident, prescribed procedure should be followed; this likely includes reporting the incident to a chairperson or coordinator to ensure that cheating cases are handled in a consistent and equitable manner.

In some cases, classroom observation is not sufficient evidence. Evidence of collusion exists when two suspected students choose the same wrong answers to several questions. At least one student probably copied from the other (Nath, 2009).

A more blatant cheating method occurs after the graded exams have been returned to the students. A student will change an answer or add to a problem or essay. The exam will then be re-submitted to the instructor, with a claim that the exam was incorrectly graded and more points should be awarded. Unfortunately, the instructor may be unable to determine if the change was made before or after the student initially submitted the exam; the instructor has little evidence. If cheating is suspected, future exams should be photocopied before they are returned for student review.

The combination of today's high-tech world and student creativity has created several innovative cheating techniques. Students with cell phones or personal data assistants (PDAs) can 'beam" or call data to students wishing to cheat via text messaging, instant messaging, e-mail, and a camera or video recorder. These electronic devices are easily concealed by students under desktops or in baggy clothing. The advent of Bluetooth technology is making this practice even easier than half a decade ago (Storm \& Storm cited in Hulsart, 2009).

\section{SECTION 9: PREVENTING CHEATING}

Instructors can avoid cheating incidents by placing emphasis on procedures to prevent cheating. Even though some of the following ideas and suggestions appear somewhat autocratic, most students will appreciate concern for the exams being administered fairly.

- A clear communication that the instructor is aware that cheating can occur is needed. The instructor (or proctor) should be present in the room, in sight of all students.

- Cheating is more likely to occur if a proctor takes the instructor's place. This is because the students are aware that a proctor might not report cheating incidents. The instructor may be less apt to prosecute if the cheating was viewed by a third party instead of the instructor personally witnessing the event.

- $\quad$ "Scrambled" multiple-choice answer sheets can deter cheating; variations of scrambled answer sheets for students sitting close together can be helpful.

- $\quad$ Control of the exam copies is important. The exams can be consecutively pre-numbered.

- Scrambling the order of the questions and the order of the pages creates at least two different exams; no two students sitting close together will have the same exam. Both versions can be on the same color paper (to conceal the fact that different exams exist) or each version can be a different color paper (no two students sitting together have the same color exam).

- $\quad$ All scrap paper should be provided. A certain color or type will prevent a student from mixing in his or her own notes with the scrap provided. All scrap paper must be submitted with the exam.

- $\quad$ A designated, alpha-order seating arrangement or a random seat switch involving several students (including the students you suspect) to separate friends and prevent sharing should be considered. The instructor should not distribute the exams until satisfied with the seating arrangements.

- $\quad$ Student access to cell phones, study materials, and personal items in the exam room should be limited.

- A policy allowing (or not allowing) students to leave the exam room should be established. If students are allowed to leave the exam room, all exam materials should be secured by the instructor; only one student should be out of the exam room at any one time. 


\section{SECTION 10: GRADING}

Most educators dislike the grading process. Determining grades that accurately reflect student performance is difficult. Even more difficult is assigning those grades to students, especially when those grades may be lower than what the students expect.

Teaching would be much more enjoyable if the grading process was eliminated, allowing educators to just teach and allowing students to just learn. This would likely result in a more enjoyable experience for both groups. However, the grading process is both indispensable and beneficial. The grading process exists for many reasons:

- $\quad$ Grades are used to distinguish students' abilities.

- $\quad$ For students, grades act as an incentive to perform on a higher level.

- $\quad$ Grades act as an objective assessment to use in counseling students. They represent a student's ability and potential in a certain curriculum or academic path. A student who receives low grades in a planned "major" should have enough evidence to reconsider continuing in that curriculum. Conversely, high grades communicate to a student that he or she could succeed in the career path represented by those courses.

- $\quad$ Grades act as a quality control system for the institution. A diploma represents the meeting of minimum standards determined by the institution; the grading process is the system that assures the quality of the graduate.

- Grades are used as an evaluation method by other groups. Although they are often criticized as being an inaccurate representation of student ability, they are still carefully considered by graduate schools and potential employers in decisions to accept or reject an applicant.

The most important section of an instructor's syllabus refers to the grade computation. Several methods of grade computation are valid, as long as the grades are based on the prescribed method in the syllabus. Instructors should consider the various methods of grade computation and select the method that best meets their teaching style and the course objectives.

A rigid, predetermined grading scale $(A=90 \%, B=80 \%)$ is sometimes viewed as the most objective and biasfree system. It helps to substantiate grades without concern for showing favoritism. A rigid grading scale assumes that the components comprising the grade (exams, homework, etc.) are weighted properly and the individual components are true representations of those grades. For example, an exam must be at the exact difficulty level so that a $90 \%$ score indicates an "A" student. An exam with a higher difficulty level will result in a "B" grade awarded to a student deserving an "A" grade. Conversely, an "A" grade is awarded to a "B" student if an easy exam is given.

The exams and other grade components should be reviewed to assure correlation with the rigid grading scale. Unfortunately, this determination might not be possible until an exam has been given at least once. If the students are scoring significantly higher or lower than their abilities (as indicated by other measurements, such as G.P.A. and inclass performance), subsequent exams should be adjusted to compensate.

A more subjective system is a "curve," which allows instructors to adjust for exams that are more difficult or easier than planned. Because there is no rigid scale to determine grades, the instructor should devise some method to estimate a student's performance during the semester and communicate that to the student.

Upon assigning final grades, the instructor should not allow the withdrawals by some students to affect the grades of the remaining students. For example, assume the instructor is comfortable with a "bell-shaped" distribution of scores during the semester and the estimated grades for 20 students are evenly distributed during the latter stages of the semester (two As, four Bs, eight Cs, four Ds and two Fs). If the lowest six students decide to withdraw from the class, the instructor should not re-curve the remaining 14 grades; some of the eight $\mathrm{C}$ students would suddenly be performing at a D or F level, solely based on the decisions of other students to withdraw.

The original eight students who were performing at a $\mathrm{C}$ level are still performing at a $\mathrm{C}$ level; they should be awarded a $\mathrm{C}$. To change their grade indicates that the instructor was using the curve simply to provide an even distribution. 
Grading is a key component of the school's quality control system. Especially in the early stages of the curriculum, certain courses act as key determinants in assuring that only competent, dedicated students continue in the curriculum. These courses may require lower grade point averages in order to meet the quality control objectives. For example, an introductory class in a particular major could be comprised of students not having the ability or interest to succeed in that major area of study. If the instructor is a lenient grader and awards high grades to undeserving students, the students get the false impression that they are qualified to continue in that academic program; they do not receive a realistic assessment of their chances to succeed until they take the more advanced courses in the curriculum. By then, changing their program without losing credits may not be possible.

Conversely, the instructor too strict in enforcing grading standards might "scare" qualified students away from the curriculum that best fits their interests and abilities. Each instructor should therefore make every effort possible to stay within a reasonable G.P.A. range for the course.

The common situation of different instructors teaching sections of the same course creates the danger of significant G.P.A. inconsistencies among instructors. Students performing at basically the same level can be evaluated very differently by different instructors. This will defeat any quality control efforts, as students will "shop" for the instructor who historically issues the highest grades. Each instructor should be concerned about this possibility and work with the department chairperson to avoid it.

When comparing the "quality control" effectiveness of a class, the G.P.A. is an important factor to consider; however, GPA should not be the sole factor. Again, the impact of withdrawing students should be considered.

For example, assume a course has two sections, one taught by Instructor $\mathrm{X}$ (a strict grader) and the other by Instructor Y (a lenient grader). Both sections have four students, with the students performing at the following levels:

$\begin{array}{cl}\text { Student } & \text { Performance Level } \\ 1 & \text { Excellent } \\ 2 & \text { Good } \\ 3 & \text { Below Average } \\ 4 & \text { Poor }\end{array}$

At the end of the semester, the two instructors are prepared to give the following grades:

Probable Grades Based On Coursework

\begin{tabular}{|c|c|c|}
\hline Student & Instructor X & Instructor Y \\
\hline 1 & A & A \\
\hline 2 & B & B \\
\hline 3 & D & B \\
\hline 4 & F & 3.50 \\
\hline $\begin{array}{l}\text { Anticipated G.P.A. before withdrawal of } \\
\text { students expecting poor grade (A=4.00) }\end{array}$ & 2.00 & \\
\hline
\end{tabular}

(Instructor $\mathrm{Y}$ is by nature more lenient than Instructor $\mathrm{X}$ )

If these grades were actually awarded, it would demonstrate the significant difference between the grading policies of Instructor $\mathrm{X}$ and Y. (2.00 G.P.A. vs. 3.50 G.P.A.) However, the difference would not be discovered if the two students anticipating a "D" and "F" withdrew from the course, assuming that the "W" grade is not used in the G.P.A. computation. The G.P.A. for both classes would be 3.50, even though Instructor Y was a much easier grader than Instructor X: 
Final Grades Following Withdrawal Of Students Expecting Poor Grade

\begin{tabular}{|c|c|c|}
\hline Student & Instructor X & Instructor Y \\
\hline 1 & $\mathrm{~A}$ & $\mathrm{~A}$ \\
\hline 2 & $\mathrm{~B}$ & $\mathrm{~A}$ \\
\hline 3 & $\mathrm{~W}$ & $\mathrm{~B}$ \\
\hline 4 & $\mathrm{~W}$ & $\mathrm{~B}$ \\
\hline Actual G.P.A. & 3.50 & 3.50 \\
\hline Non-success Rates & $50 \%$ & $0 \%$ \\
\hline
\end{tabular}

For this reason, both the G.P.A. and the "non-success rate" should be used to evaluate the grading policies of an instructor. The difference in non-success rates (50\% for Instructor $\mathrm{X}$ and $0 \%$ for Instructor $\mathrm{Y}$ ) would represent the tougher grading policies of Instructor $\mathrm{X}$, who was set to give the " $\mathrm{D}$ " and "F" grades.

All instructors should be aware of the various final grades allowable, including the traditional grades (A through F) and other grades (Withdrawal, Incomplete, Audit, etc.) used in special circumstances. Specific conditions and time restraints are usually associated with these particular grades.

The "Incomplete" grade is often misused by instructors to allow students more time to complete "extra credit" work, thereby raising their grade to an acceptable level. The allowance of such "extra credit" work for selected students may be inappropriate, as it is only available to the students who request it.

Changing a grade should only occur when an instructor realizes that an error has occurred. However, instructors too often are confronted by a student dissatisfied with a final grade and will take the easy course of changing the grade, possibly allowing "extra credit" work to be used in re-computing the grade. Instructors who do this will quickly build a reputation on campus and should expect additional grade appeals in future semesters.

Computations of the final grades are important enough to perform twice. The instructor should envision all students appealing the final grade, especially those receiving low grades. Does adequate support for the final grade exist? Was it calculated according to the system cited in the syllabus? Careful grade computation will minimize student appeals.

"Extra credit" work allowed for a student is often equivalent to "extra time" allowed for a student taking an exam: it is unfair to all other students who did not receive the special consideration to improve their grade. It also violates the grading system explained in the syllabus.

All instructors should maintain adequate records to document and support the students' grade computations. This documentation is critical in the event of any grade appeals and should be kept for the time prescribed by academic policy.

\section{CONCLUSION}

To be effective, instructors must demonstrate a commitment to education and a true desire to maximize classroom effectiveness. However, the realities of college teaching also require instructors to assign grades that are representative of student learning and the meeting of course objectives.

Student assessment vehicles, such as exams, must be properly designed and administered for those grades to be representative. Because students consider those grades vital to their academic success and career potential, some of them may cheat to increase their chance of successful course completion or to improve their course grade. Instructors should be aware of these realities and accordingly place emphasis on the development of appropriate exams, the proper administration of exams, and the effect of student cheating on the exam results. 


\section{ABOUT THE AUTHOR}

Richard D. Berschback, is Chair of the Accounting Department at Walsh College, a Detroit-area upper-division college specializing in business undergraduate and graduate degrees. Rick has taught Intermediate Accounting and Auditing for over 30 years and has public accounting experience with PricewaterhouseCoopers and Ernst \& Young. $\mathrm{He}$ received the first annual Michigan Accounting Educator of the Year Award in 2002 from the Michigan Association of CPAs and also earned the MACPA 2003 Distinguished Achievement in Accounting Education Award. Rick holds both undergraduate and graduate degrees from the University of Detroit. Email Address: rberschb@walshcollege.edu.

\section{REFERENCES}

1. Crittenden, V. L., Hanna, R. C., \& Peterson, R. A. (2009). The cheating culture: A global societal phenomenon. Business Horizons, 52(4), 337-346. doi: 10. 1016/j.bushor.2009.02.004.

2. Elikai, F., \& Schuhmann, P. W. (2010). An examination of the impact of grading policies on students' achievement. Issues In Accounting Education, 25(4), 677-693. doi: 10.2308/iace.2010.25.4.677.

3. Holtzman, M. (2008). Demystifying application-based multiple-choice questions. College Teaching, 56(2), 114-120.

4. Hulsart, R., \& McCarthy, V. (2009). Educators' role in promoting academic integrity. Academy of Educational Leadership Journal, 13 (4), 49-60.

5. Kwan, F. B. (2010). True/false test: Enhancing its power through writing. Journal of Instructional Pedagogies $4(1), 9$.

6. Nath, L., \& Loveglia, M. (2009) Cheating on multiple-choice exams. College of Teaching, 57(1), 3-8.

7. Owunwanne, D., Rustagi, N., \& Dada, R. (2010). Students' perceptions of cheating and plagiarism in higher institutions. Journal of College Teaching and Learning, 7, 59-68.

8. Scouller, K. (1998). The influence of assessment method on students' learning approaches: Multiple choice question examination versus assignment essay. Higher Education, 35(4), 453-472. 
NOTES 